\title{
AN AUTOMATED FLUOROMETER FOR URANIUM ANALYSIS
}

\author{
R. J. McElhaney \\ J. D. Caylor \\ S. H. Cole \\ T. L. Futrell \\ V. M. Giles
}

March 1978

Adapted from a Paper that was Presented at the 21st Annual Conference on Analytical Chemistry in Energy Technology, Gatlinburg, Tennessee, October 4-6, 1977.

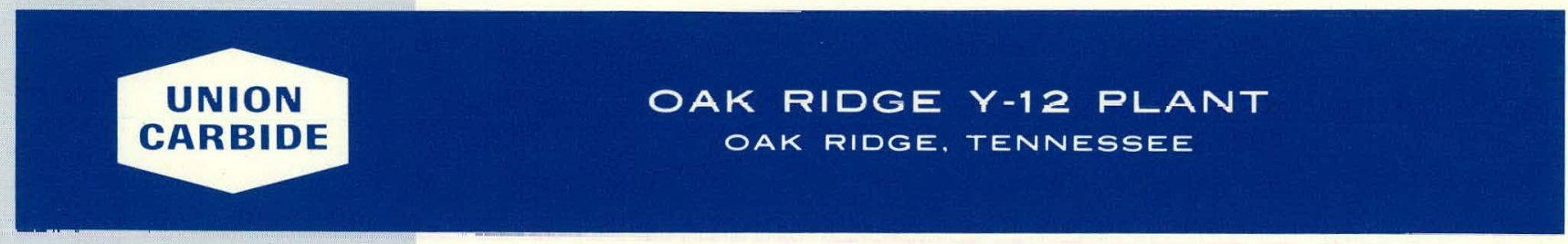

prepared for the U.S. DEPARTMENT OF ENERGY under

U.S. GOVERNMENT Con tract W-7405 eng 26

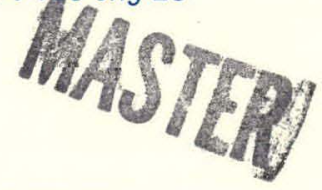




\section{DISCLAIMER}

This report was prepared as an account of work sponsored by an agency of the United States Government. Neither the United States Government nor any agency Thereof, nor any of their employees, makes any warranty, express or implied, or assumes any legal liability or responsibility for the accuracy, completeness, or usefulness of any information, apparatus, product, or process disclosed, or represents that its use would not infringe privately owned rights. Reference herein to any specific commercial product, process, or service by trade name, trademark, manufacturer, or otherwise does not necessarily constitute or imply its endorsement, recommendation, or favoring by the United States Government or any agency thereof. The views and opinions of authors expressed herein do not necessarily state or reflect those of the United States Government or any agency thereof. 


\section{DISCLAIMER}

Portions of this document may be illegible in electronic image products. Images are produced from the best available original document. 
Reference to a company or product name does not imply approval or recommendation of the product by Union Carbide Corporation or the Department of Energy to the exclusion of others that may meet specifications.

Printed in the United States of America. Available from National Technical Information Service

U.S. Department of Commerce 5285 Port Royal Road, Springfield, Virginia 22161

Price: Printed Copy $\$ 4.00$; Microfiche $\$ 3.00$

This report was prepared as an account of work sponsored by an agency of the United States Government. Neither the United States Government nor any agency thereof, nor any of their employees, nor any of their contractors, subcontractors, or their employees, makes any warranty, express or implied, nor assumes any legal liability or responsibility for any third party's use or the results of such use of any information, apparatus, product or process disclosed in this report, nor represents that its use by such third party would not infringe privately owned rights. 


\title{
AN AUTOMATED FLUOROMETER FOR URANIUM ANALYSIS
}

\author{
R. J. McElhaney \\ J. D. Caylor \\ S. H. Cole \\ T. L. Futrell \\ V. M. Giles \\ Y-12 Plant Laboratory \\ Product Certification Division
}

Adapted from a Paper that was Presented at the 21st Annual Conferense on Analytical Chemistry in Energy Technology, Gatlinburg, Tennessee, October 4-6, 1977.

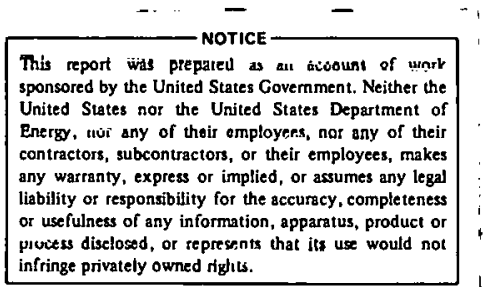

Oak Ridge Y-12 Plant

P. O. Box Y, Oak Ridge, Tennessee 37830

Prepared for the Department of Energy Under US Government Cuntract W.7106-eng=26 


\begin{abstract}
An automated fluorometer has proven to be a valuable analytical tool for analyzing natural waters for the Uranium Resource Evaluation (URE) project. Uranium is isolated from potential quenching ions and concentrated by extraction with tri-n-octylphosphine oxide (TOPO) in Varsol. A portion of the extract is placed on a sodium fluoride pellet which is then dried, sintered, and cooled. Sixteen samples can be analyzed in about 1.5 hours. The lower reporting limit has been set at 0.20 micrograms per liter $(\mu \mathrm{g} / 1)$.
\end{abstract}




\section{CONTENTS}

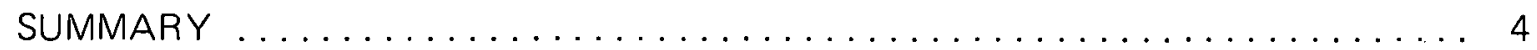

INTRODUCTION $\ldots \ldots \ldots \ldots \ldots \ldots \ldots \ldots \ldots \ldots \ldots \ldots \ldots \ldots \ldots \ldots \ldots \ldots \ldots \ldots$

FLUORESCENCE URANIUM ANALYSIS $\ldots \ldots \ldots \ldots \ldots \ldots \ldots \ldots \ldots \ldots$

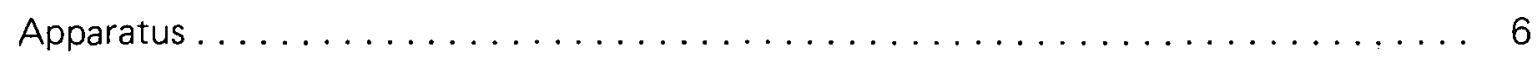

Standards and Reagents .................................. 10

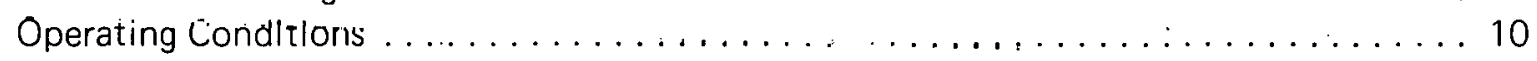

Procedure ....................................... 11

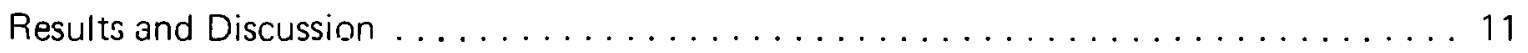

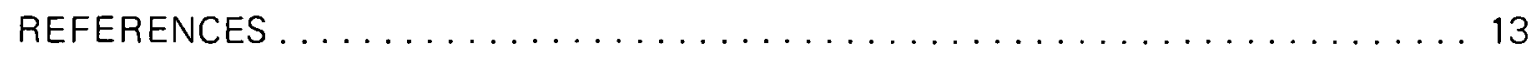




\section{SUMMARY}

An automated fluorometer for uranium analysis has proven to be a valuable analytical tool for monitoring industrial process and waste streams for accountability purposes, and for analyzing natural waters for the Uranium Resource Evaluation (URE) project. The classical flame-fusion method has been replaced by a furnace-sintering method that reduces or eliminates much of the imprecision found in the fusion process. Uranium is isolated from potential quenching ions and concentrated by extraction with tri-n-octylphosphine oxide (TOPO) in Varsol. A portion of the extract is placed on a sodium fluoride pellet which is then dried, sintered, and cooled. Standards are carried through with the samples and provide calibration data. Sixteen samples can be analyzed in about 1.5 hours. The lower reporting limit has been set at 0.20 micrograms per liter $(\mu \mathrm{g} / \mathrm{l})$. 


\section{INTRODUCTION}

Fluorometry has been used successfully for many years for the analysis of uranium in a variety of matrices. 1 - 3 The usual method of preparation has involved extraction of the uranium with a subsequent flame fusion on a $98 \%$ sodium fluoride- $2 \%$ lithium fluoride pellet. However, the flame-fusion method has many variables which can lead to wide fluorescence variations and which require considerable skill to control. A furnace-sintering method using sodium fluoride pellets was investigated at the Oak Ridge Y-12 Plant(a) as an alternative to the flame-fusion method. Concurrently, a programmable-calculator-controlled, 40-position fluorometer was constructed to provide rapid analysis of a large number of samples. Combining furnace sintering with the automated fluorometer was found to be ideally suited for a ruuline laburatory analysis of hundreds of samplos por wook.

(a) Operated by the Union Carbide Corporation's Nuclear Division for the Department of Energy. 


\section{FLUORESCENCE URANIUM ANALYSIS}

\section{APPARATUS}

Sodium fluoride pellets used for the fluorescence analysis were produced by using a Stokes pill press equipped with a 3/8-inch die. Fluorometric-grade sodium fluoride was used to produce pellets weighing 0.28 gram each. Actual production of pellets was highly dependent upon the bulk density of the starting material. A full discussion of the pellet-production problem would be inappropriate here. Suffice it to say that production of suitable sodium fluoride pellets is a continuing challenge.

Figure 1 presents a view of the fluorometer and associated equipment. The instrument consists of a 40-position sample slide on a motorized loader which passes under a

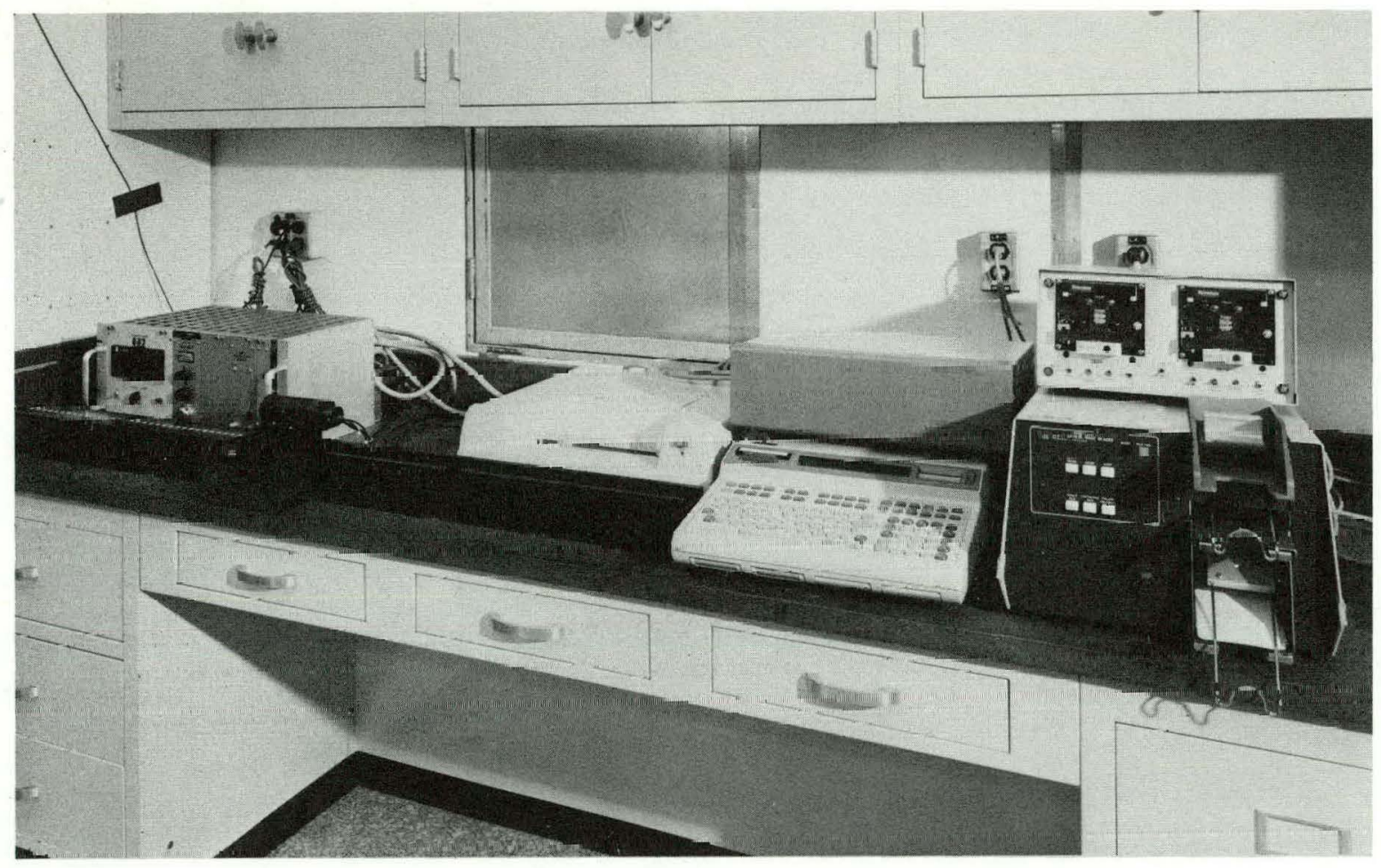

Figure 1. FLUOROMETER WITH ITS ASSOCIATED EQUIPMENT.

175241

combination mercury arc lamp/photomultiplier detector with an interference filter to isolate the 550-nm fluorescence. The amplified fluorescence intensity is fed to an on-line calculator for standards calibration and sample calculation. Figure 2 is a closeup view of the automated sample loader and detector assembly. The sample loader consists of a base unit with a machined sample tray and a 40-position sample slide. The base unit was constructed from three aluminum plates and is 58 inches in length. The excitation and detector assembly was removed from a Jarrell-Ash Galvanek-Morrison Fluorometer, Mark $V$, and positioned in the center of the base unit. The sample-tray drive motor, ballasts for the excitation lamps, 


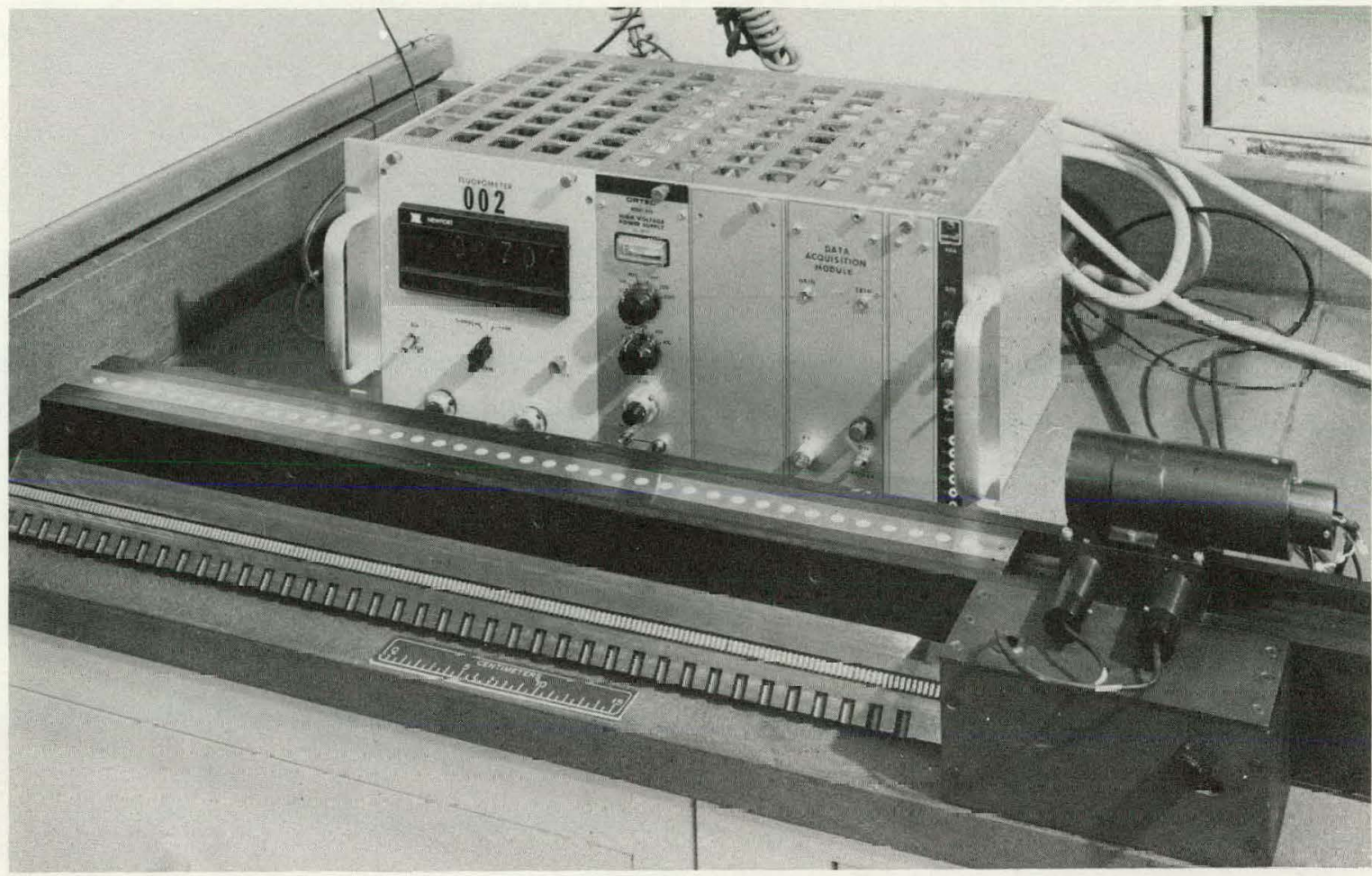

Figure 2. CLOSEUP OF THE FLUOROMETER.

175240

and the control microswitches are mounted within the base unit. The sample tray is 26 inches long and is a machined block of tool steel. The sample tray has grooves machined in the bottom to operate the microswitches which turn on the detector high voltage and initiate the printout sequence for each of the sample positions. The sample slide was also machined from tool steel and contains forty 11/32-inch-diameter holes which position the pellets in the tray.

Figure 3 is a block diagram of the fluorometer electronics. The output of the photomultiplier is coupled to a high-impedance preamplifier which functions as a current-to-voltage converter. The signal is then applied to a variable-gain amplifier with provision for dark-current suppression. The output of this amplifier appears as a series of near-Gaussian peaks as the pellets pass under the detector. To simplify the data-acquisition software, an analog peak detector is incorporated and utilizes two operational amplifiers, a field-effect-transistor (FET) switch, and a low-leakage polystyrene capacitor. The peak output is read by a digital voltmeter whose parallel binary-coded-decimal (BCD) outputs are interfaced to a programmable calculator. The peak detection sequence is controlled by relatively simple digital circuitry which receives a $\overline{\text { PRINT }}$ command from a microswitch in the base unit. The system sequencing can best be understood by observing the analog waveform and timing diagram in Figure 4. The output of the variable-gain amplifier is represented by the Gaussian peaks. The shaded areas depict how the peak holder effectively holds the maximum of each peak until this value has been passed to the calculator. The $\overline{\mathrm{PRINT}}$ command is initiated by groovos machined in the bottom of the sample tray. The 


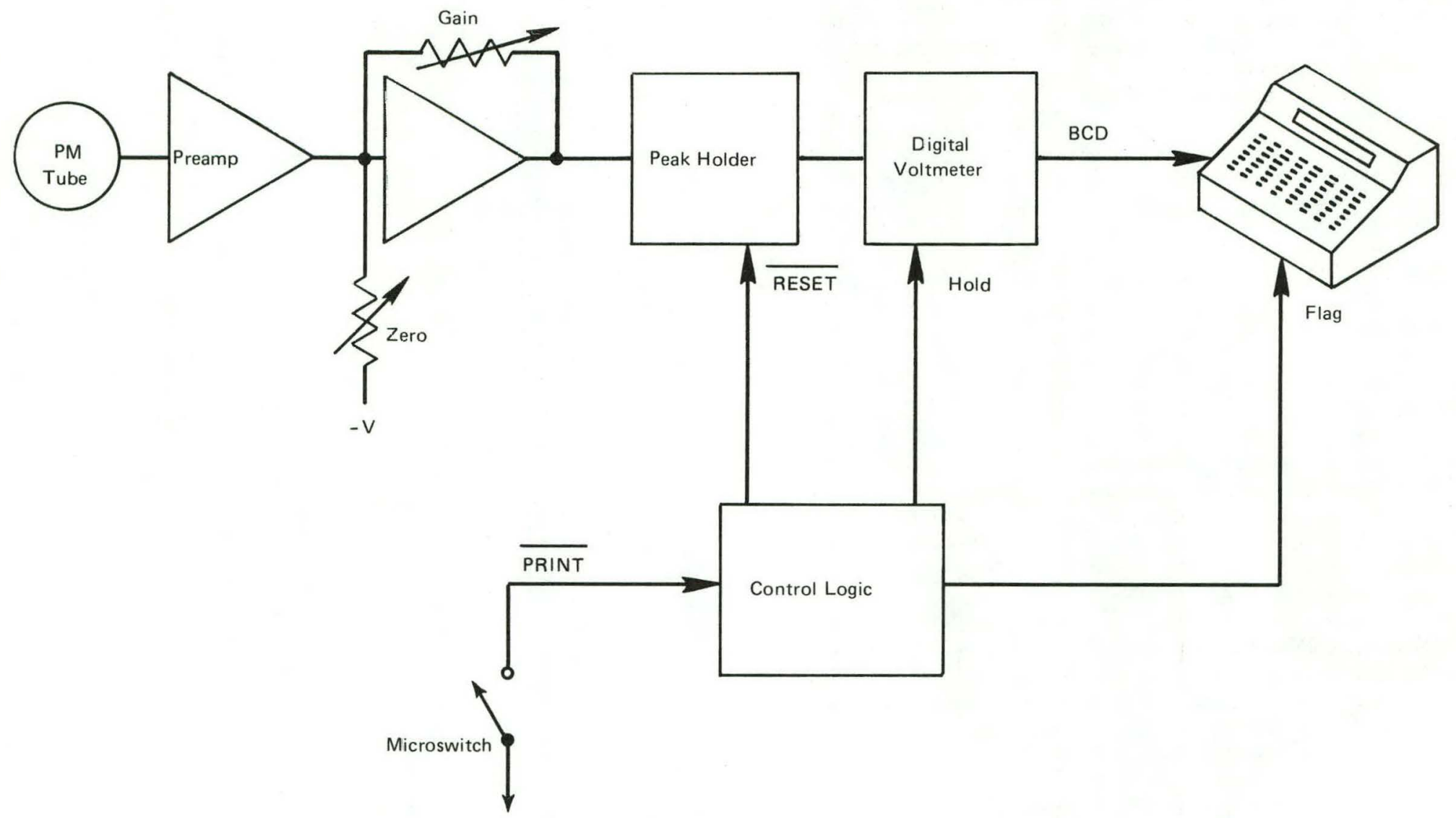

Figure 3. PRINCIPAL COMPONENTS OF THE FLUOROMETER SYSTEM. 


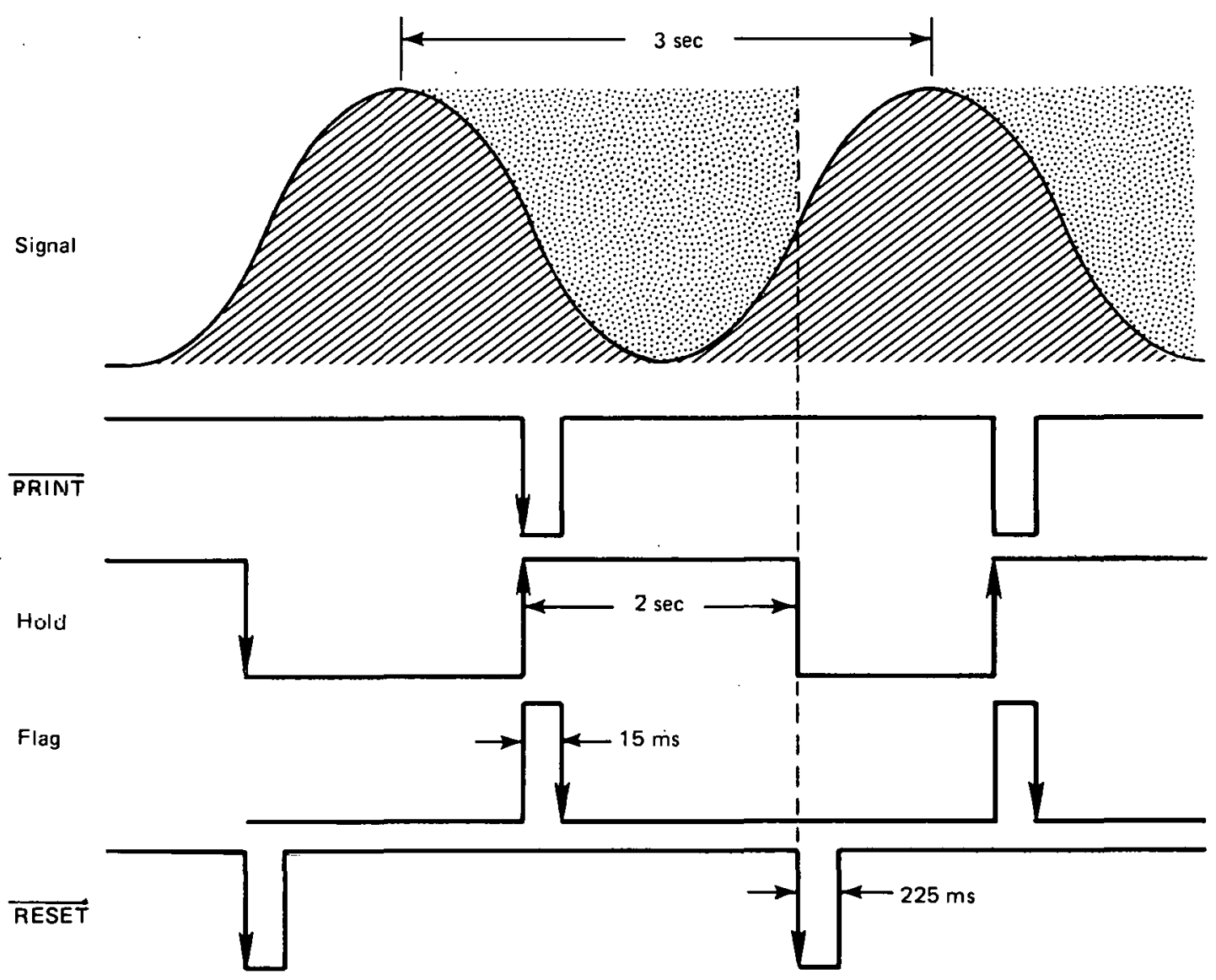

Figure 4. SYSTEM TIMING SEQUENCE.

switch position is such that the $\overline{\mathrm{PRINT}}$ command is received after the peak maximum has been attained. The $\overline{\text { PRINT }}$ command generates a HOLD signal which causes the digital voltmeter to hold the peak output for two seconds. After the HOLD condition has been in effect for fifteen milliseconds, a FLAG is generated which signals the calculator to accept the data. After the conclusion of the HOLD signal, a $\overline{R E S E T}$ command discharges the capacitor that is storing the peak analog. Note that the $\overline{\mathrm{RESET}}$ signal is not applied until the detector is already following the leading edge of the next peak. This sequence is then repeated for each of the 40 positions. The complete electronics package is housed in a five-wide NIM module. The analog and digital circuits are fabricated on separate printed circuit boards within the module. An additional module is required for the detector power supply.

The fluorometer was initially interfaced to a Hewlett-Packard 9821A programmable calculator which was used to acquire data, perform a linear fit to the standards, and calculate sample concentrations. Use of the calculator completely eliminated the need to calibrate the system electronics. While the fluorometer used only a fraction of the calculator's capability, it was necessary to dedicate the calculator due to the lack of an interrupt capability that would allow simultaneous data acquisition from other instruments. The fluorometer is now interfaced to a Hewlett-Packard $9825 \mathrm{~A}$ calculator which does have 
interrupt capability, so it may be operated simuitaneously, yet independently, with another automated instrument.

\section{STANDARDS AND REGENTS}

A description of the solutions that are required in this analysis follows.

TOPO Solution, $0.05 \mathrm{M}$

Dissolve $100 \mathrm{~g}$ of TOPO in $1000 \mathrm{ml}$ of Varsol. Apply heat to aid dissolution. Dilute to 5 liters with $\mathrm{Varsol}$ in a suitable container, and mix well.

\section{Uranium Stock Sọlution I, $1000 \mu \mathrm{g} / \mathrm{ml}$}

Dissolve 0.5896 gram of $\mathrm{U}_{3} \mathrm{O}_{8}$ in $20 \mathrm{ml}$ of $\mathrm{HNO}_{3}(1: 1)$ and slowly evaporate the solution to near dryness. Dissolve the residue with $10 \mathrm{ml}$ of $\mathrm{HNO}_{3}(1: 99)$ and transfer the solution to a 500-ml volumetric fläsk. Dilute to volume with $\mathrm{HNO}_{3}$ (1:99), and mix well.

\section{Uranium Stock Solution II, $100 \mu \mathrm{g} / \mathrm{ml}$}

Dilute $10 \mathrm{ml}$ of Stock Solution I to volume in a $100-\mathrm{ml}$ volumetric flask with $\mathrm{HNO}_{3}(1: 99)$, and mix well.

\section{Uranium Stock Solutions III and IV, 2 and $0.1 \mu \mathrm{g} / \mathrm{mI}$}

Dilute 20 and $1 \mathrm{ml}$, respectively, of Stock Solution 11 to volume in $1000-\mathrm{ml}$ volumetric flasks with $\mathrm{HNO}_{3}$ (1:99), and mix well.

\section{Uranium Standard Solutions V and VI, 10 and $0.5 \mu \mathrm{g} / \mathrm{I}$}

Dilute $10 \mathrm{ml}$ of Stock Solutions $11 \mathrm{I}$ and IV, respectively, to volume in 2000-ml volumetric flasks.with $10 \mathrm{ml}$ of $\mathrm{HNO}_{3}$ and water, and mix well.

\section{OPERATING CONDITIONS}

The choice of operating conditions was based on two considerations: (1) maximizing analysis sensitivity, and (2) minimizing analysis time. Sodium fluoride pellets were mass produced to handle an expected large sample load, and two pellets were processed for each sample and standard to minimize slight variations in pellet weight and density. The largest sample volume that could be loaded on a pellet without soaking through was $0.050 \mathrm{ml}$. An evaporation time of 20 minutes under infrared lamps was found to be adequate. The temperature of the sintering furnace had to be as high as possible to maximize fluorescent intensity. without melting the pellet and still produce pellets that would fit into the holes drilled in the sample slide. (This temperature was found to be $\sim 960^{\circ} \mathrm{C}$, using an optical pyrometer.) The time in the furnace was chosen by adding five minutes to the minimum 
time it took a tray of pellets to reach thermal equilibrium and produce consistent fluorescent intensities from the front to the back of the tray (20 minutes). Twenty minutes was also found to be an adequate cooling time before intensity measurements were made.

\section{PROCEDURE}

A 40-ml portion of each sample was placed in a $50-\mathrm{ml}$ plastic centrifuge cone and acidified with $1 \mathrm{ml}$ of $\mathrm{HNO}_{3}$. One $\mathrm{ml}$ of the T.OPO-in-Varsol solution was added to each cone, the cones capped, and the samples extracted on a shaker for 10 minutes. After the phases had separated, $0.050-\mathrm{ml}$ portions of the extract were placed on two sodium fluoride pellets. The pellets sat in 11/16-inch-diameter platinum dishes, with 40 dishes accommodated on a lava liay. Tuvi standard uranium solutions of 0.5 and $10 \mu \mathrm{g} / \mathrm{l}$ were processed along with each batch of samples, except that four pellets for each standard were prepared. This provision left 32 positions on the tray and, with two pellets per sample, the number of samples in a batch was 16. A fully loaded tray was then placed under the lights for 20 minutes, siritered at $\sim 960^{\circ} \mathrm{C}$ for 20 minutes, and cooled for 20 minutes. Two pellets of the 10 -ppb standard were loaded into Positions 1 and 2, and two pellets of the 0.5-ppb standard were loaded in Positions 3 and 4 . The other standard pellets and sample pellets filled the remaining positions. The sample slide motor and calculator program were started and fluorescent intensity measurements made at each sample position.

\section{RESULTSS AND DISCUSSION}

Figure 5 shows an example of the calculator output of a typical run. The first four lines are the fluorescent intensities of the calibrating standards, followed by sample information. Each sample has the fluorescent intensity of both pellets, a line of sample identification information, and the calculated result printed in $\mu \mathrm{g} / \mathrm{l}$. The first two samples happen to be the 0.5 and $10-\mu \mathrm{g} / /$ standards used to check the calibration of each run. The intensities of Sample 4 are at the detector saturation limit; and the result is meaningless. In such a case, the detector voltage would have to be reduced to get real intensity measurements with a sacrifice of some sensitivity. Under normal operating conditions, a lower reporting limit of $0.20 \mu \mathrm{g} / \mathrm{l}$ is nhtained, with an upper saturation limit of about $50 \mu \mathrm{g} / \mathrm{l}$. The variation of intensity from two buttons of the same sample are fairly typical.

As part of the URE project, a quality control program was initiated to determine the accuracy and precision of the method. Two control batches were anonymously submitted and analyzed as real samples. The uranium values of the two batches were 0.52 and $9.90 \mu \mathrm{g} / \mathrm{l}$. From May 1976 through June 1977, 87 of the $0.52 \mu \mathrm{g} / \mathrm{l}$ controls were analyzed and yielded a mean and standard deviation of $0.540 \pm 0.098 \mu \mathrm{g} / \mathrm{l}$. In the same period, $92 \mathrm{of}$ the $9.90-\mu \mathrm{g} / 1$ controls were analyzed and yielded a mean and standard deviation of $10.314 \pm 0.620 \mu \mathrm{g} / \mathrm{l}$. Also, during that same period, neaily 6000 samples were analyzed.

The automated fluorometer has proven to be one of the most reliable laboratory instruments, giving near trouble-free operation. One notable exception occurred recently. Quality control status reports were indicating deviations from the mean much greater than 


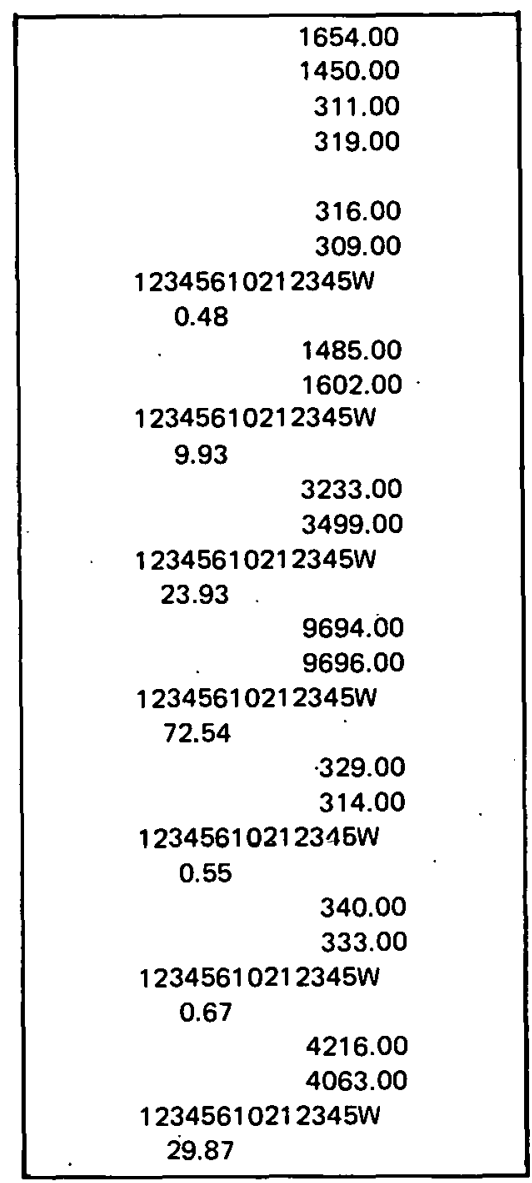

Figure 5. CALCULATOR OUTPUT.

usual on several control programs. A thorough recheck of all operating conditions turned up nothing to explain the situation. Finally it was discovered that, somehow, the sample tray and slide had become magnetized. The photomultiplier detector is sensitive to magnetic fields and was giving false fluorescence measurements. The sample tray and slide were thoroughly degaussed, temporarily eliminating the problem. A sample tray and slide will be fabricated from brass to permanently eliminate the problem.

In conclusion, use of the furnace-sintering method in conjunction with an automated fluorometer has made the fluorescence analysis of uranium in process streams and natural waters an accurate, reliable, and routine laboratory procedure. 


\section{REFERENCES}

1. Price, G. R., Ferretti, R. J., and Schwartz, S.; Anal Chem, 25, p 322 (1953).

2. Centanni, F. A., Ross, A. M., and DeSesa, M. A.; Anal Chem, 28, p 1651 (1956).

3. Owens, J. W.; Fluorometric Determination of Uranium in Environmental Materials, LA-6338-MS; Los Alamos Scientific Laboratory, Los Alamos, NM; May 1976. 


\section{Distribution}

Bendix Field Engineering -

Grand Junction

Steinborn, T.

Department of Energy - Ames Laboratory

D'Silva, A.

Fassel, V. A.

Department of Energy - Grand Junction

Boyer, B.

Grutt, E.W., Jr

Malan, R. C.

Roach, C. H.

Shannon, S.

Department of Energy - Oak Ridge

Butts, D. D.

Hickman, H. D.

Leed, R. E.

Scott, T. H.

Zachry, D. S. Jr

Lawrence Livermore Laboratory

Tinney, J. F.

Los Alamos Scientific Laboratory

Abernathy, R. M.

Sharp, R. R.

Oak Ridge Gasẹous Diffusion Plant

Arendt, J.W.

Butz, T. R.

Cagle, G.W.

Levin, R.W.

Nichols, C. E.

Stief, S. S.

Weber, C. W.

Wilcox, W. J., Jr

Oak Ridge National Laboratory

Carter, J. A.

Shults, W. D.

Walker, R. C.
Oak Ridge $Y-12$ Plant

Bernander, N. K.

Briscoe, O. W.

Burditt, R. B.

Cole, S. H. (5)

Duggan, H. G.

Flynn, A. R.

Fraser, R. J.

Futrell, T. L. (5)

Giles, V. M.

Jones, F.W.

Kahl, K. G.

Keith, A.

Kite, H. T. (15)

Martin, W. R./Googin, J. M.

Mason, D. L./Schreyer, J. M.

McBryde, W. T.

McElhaney, R. J. (5)

McLendon, J. D.

Mills, J. M., Jr

Morrow, R. W. (5)

Phillips, L. R.

Rhew, J. E.

Smith, H. F., Jr

Smith, R. D.

Tewes, W. E.

White, J. C.

Y-12 Central Files (master copy)

$Y-12$ Central Files (route copy)

$Y-12$ Central Files ( $Y$-12RC)

$Y: 12$ Central Files (25)

Paducah Gaseous Diffusion Plant

Bewley, H. D.

Savannah River Laboratory

Folger, R. L.

In addition, this report is distributed in accordance with the category UC-51, Nuclear Raw Materials, as given in the DOE Standard Distribution Lists for Unclassified Scientific and Technical Reports, TID-4500. 